03

\title{
Лазероиндуцированный режим сверхинтенсивного пузырькового кипения
}

\author{
(С) В.И. Юсупов, ${ }^{1}$ В.М. Чудновский, ${ }^{2}$ В.Н. Баграташвили ${ }^{1}$ \\ ${ }^{1}$ Институт фоотонных технологий ФНИЦ „Кристаллография и фотоника“ РАН, \\ 108840 Москва, Троицк, Россия \\ ${ }^{2}$ Тихоокеанский океанологический институт им. В.И. Ильичева ДВО РАН, \\ 690041 Владивосток, Россия \\ e-mail: iouss@yandex.ru
}

(Поступило в Редакцию 16 марта 2018 г. В окончательной редакции 18 июня 2018 г.)

\begin{abstract}
Реализован режим сверхинтенсивного пузырькового кипения (СПК) в необезгаженной воде на торце лазерного волокна под действием $100 \mathrm{~ns}$ импульсного лазерного излучения. В качестве источника излучения использовался волоконный тулиевый лазер умеренной мощности с длиной волны $1.94 \mu \mathrm{m}$. Процесс генерации пузырьковых микроструй вблизи торца лазерного волокна изучен с помощью скоростной съемки и акустических методов. Показано, что в режиме СПК, переход к которому носит пороговый характер, основная энергия сигнала акустической эмиссии находится в звуковом диапазоне от 10 до $30 \mathrm{kHz}$. При этом генерация акустического сигнала происходит по механизму термокавитации. В режиме СПК достигнуты рекордные значения тепловых потоков до $0.16 \mathrm{MW} / \mathrm{cm}^{2}$. Определены параметры образующихся конвективных потоков, микропузырьков и генерирующихся широкополосных акустических колебаний.
\end{abstract}

DOI: 10.21883/JTF.2019.01.46958.114-18

В работе режим сверхинтенсивного пузырькового кипения (СПК) [1] с рекордными значениями тепловых потоков реализован на сосредоточенном источнике торце лазерного волокна в необезгаженной жидкости при использовании импульсного лазерного излучения. Впервые режим теплообмена, названный СПК, был получен с помощью проволочного нагревателя [1]. Было установлено, что при стабилизации температуры нагревателя в режиме пузырькового кипения можно получить гигантские удельные тепловые потоки (в воде до $5 \mathrm{~kW} / \mathrm{cm}^{2}$ ). В отличие от так называемого режима „микропузырькового кипения“ (MEB - microbubble emission boiling) [2,3] рекордные величины теплового потока в воде достигались без принудительной конвекции. При СПК образуются микроструи, состоящие из двухфазных потоков, направленных от поверхности нагревателя в объем жидкости в произвольных направлениях независимо от силы тяжести. При этом скорости потока в микроструях достигают $0.5 \mathrm{~m} / \mathrm{s}$ [4]. Характерным для режима СПК $[1,4]$ является генерация широкополосных акустических шумов, кавитационная эрозия поверхности нагревателя и пороговый по мощности характер возбуждения.

Недавно было экспериментально обнаружено возникновение режима СПК воды, инициированного нагревом торца оптического волокна непрерывным лазерным излучением [5]. Для создания квазиточечного источника тепла рабочий торец лазерного волокна покрывался тонким слоем углерода, в котором поглощалась значительная часть лазерной энергии. Величина отводимого от разогретого торца в воду удельного потока тепла при этом достигла $\sim 7 \mathrm{~kW} / \mathrm{cm}^{2}$, что больше величины, полученной на проволочном нагревателе [1,5]. Реализо- ванный в необезгаженной жидкости на сосредоточенном источнике - торце лазерного волокна - режим СПК представляет исключительный интерес для развития новых медицинских лазерных технологий, основанных на лазерном конвекционном нагреве биологических тканей [6]. В настоящей работе лазероиндуцированный режим СПК получен в необезгаженной воде на торце волокна без поглощающего покрытия.

Эксперименты проводились в прозрачной кювете с водой при температуре $22^{\circ} \mathrm{C}$. В качестве источника лазерного излучения использовался тулиевый лазер с длиной волны $\lambda=1.94 \mu \mathrm{m}$, длительностью импульсов $\tau=100 \mathrm{~ns}$, частотой следования импульсов $100 \mathrm{kHz}$ и мощностью до $20 \mathrm{~W}$ (ИРЭ Полюс), снабженным кварцевым волокном с диаметром светопроводящей сердцевины $125 \mu \mathrm{m}$. Во всех экспериментах мощность лазерного излучения на выходе волокна составляла $P=20 \mathrm{~W}$. Инфракрасное излучение с длиной волны $1.94 \mu \mathrm{m}$ очень хорошо поглощается в воде (коэффициент поглощения а составляет $92 \mathrm{~cm}^{-1}$ [7]). Гидродинамические процессы вблизи погруженного в воду торца волокна регистрировались высокоскоростной камерой Fastcam SA3 (Photron, Япония) на скорости 10000 кадров $s$; акустические сигналы в диапазоне от 0 до $200 \mathrm{kHz}-$ гидрофоном 8100 (Брюль и Къер) и запоминающим осциллографом GDS 72304 (GW Instek).

При включении лазера вблизи торца лазерного волокна появляется струя, состоящая из большого количества микропузырьков (рис. 1).

На кадре скоростной съемки (см. рис. $1, b)$ видно, что микропузырьки (диаметром от 10 до $50 \mu \mathrm{m})$ рождаются у торца лазерного волокна, а скорость их перемещения с удалением от торца уменьшается по экспоненциаль- 


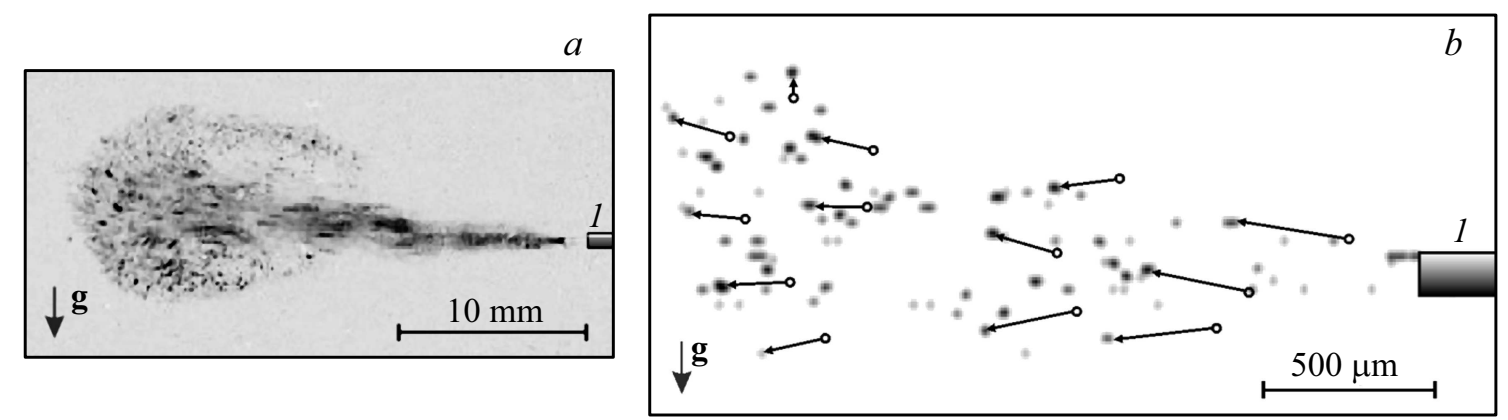

Рис. 1. Генерация микропузырьков вблизи торца лазерного волокна. $a$ - область с микропузырьками через $1 \mathrm{~s}$ после включения лазера; $b$ - распределение микропузырьков и их перемещение вблизи торца. Кружками со стрелками показаны предыдущие положения микропузырьков за $3 \mathrm{~ms}$ до этого момента. 1 - торец лазерного волокна (изображен схематично). Стрелкой показано направление силы тяжести.

ному закону. Величина отводимого от торца волокна в воду удельного потока тепла при этом составляет $0.16 \mathrm{MW} / \mathrm{cm}^{2}$, что значительно больше величин, достигнутых ранее в $[1,5]$.

Эксперименты показали, что при превышении порогового уровня $(P \sim 0.4 \mathrm{~W})$ резко возрастает мощность генерируемых акустических сигналов. При этом в режиме СПК $(P>0.4 \mathrm{~W})$ основная энергия сигнала акустической эмиссии находится в звуковом диапазоне от 10 до $30 \mathrm{kHz}$ (рис. 2). На спектре сигнала отчетливо выделяется узкий пик 1 , соответствующий частоте генерации лазерных импульсов $100 \mathrm{kHz}$.

Мы полагаем, что механизм генерации акустического сигнала связан с термокавитацией [8]. При излучении лазерного импульса вблизи торца лазерного волокна в воде благодаря хорошему поглощению лазерного излучения формируется небольшая по объему нагретая область. Оценим ее геометрические параметры. Толщина слоя воды, в котором поглощается 95\% энергии лазерного импульса, составляет $h=-\ln (0.05) / a \approx 325 \mu \mathrm{m}$, где $a=92 \mathrm{~cm}^{-1}$ - коэффициент поглощения. По фор-

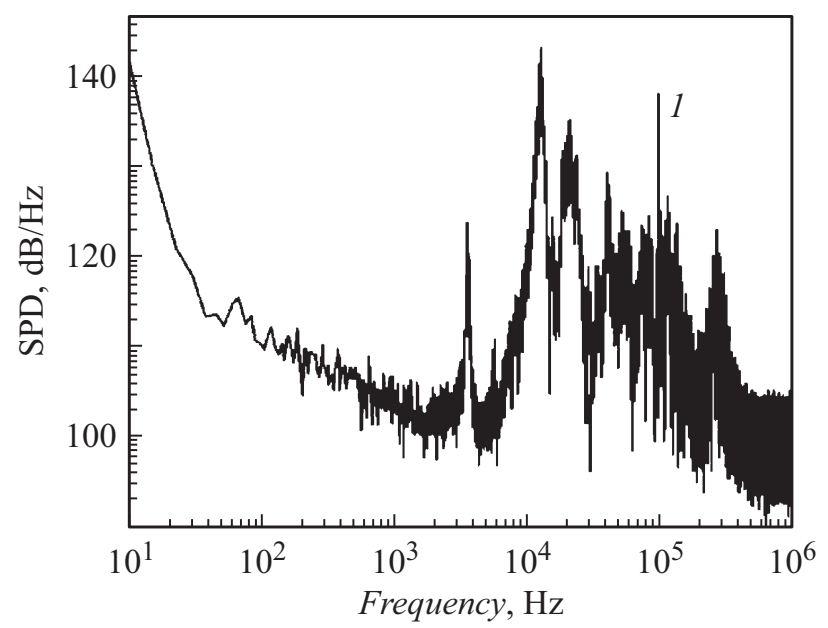

Рис. 2. Спектральная плотность мощности акустического сигнала при генерации СПК. 1 - пик, соответствующий частоте лазерных импульсов. ме такая область из-за расходимости лазерных лучей (числовая апертура волокна $N A=0.22$ ) представляет собой усеченный конус. Объем такой области составляет $V \sim 0.01 \mathrm{~mm}^{3}$, при этом в ней за один лазерный импульс поглощается $E=0.95 P / F=190 \mu \mathrm{J}$, где $P-$ мощность излучения, $F=100 \mathrm{kHz}$ - частота импульсов. Легко оценить, что без учета теплопередачи к концу лазерного импульса $(100 \mathrm{~ns})$ при $P=20 \mathrm{~W}$ средняя температура этого небольшого объема жидкости увеличится на несколько градусов. При этом вода вблизи торца волокна из-за экспоненциального уменьшения интенсивности лазерного излучения нагреется сильнее. Такой периодический нагрев воды с частотой излучения лазерных импульсов $(100 \mathrm{kHz})$ за счет термоупругих напряжений приведет к генерации акустических волн на частоте $100 \mathrm{kHz}$, что и наблюдается в эксперименте (1 на рис. 2). Эффективность механизма такой генерации звука не будет высокой, поскольку в нашем случае длительность лазерного импульса $\tau=100 \mathrm{~ns}$ превышает характерное время $t_{s}$ распространения упругих колебаний через нагретый объем жидкости [9]: $t_{s}=1 /\left(\mu_{a} c_{s}\right) \approx 70 \mathrm{~ns}$, где $c_{s}=1480 \mathrm{~m} / \mathrm{s}$ - скорость звука в воде. В условиях слабой теплопередачи температура области вблизи торца волокна с каждым последующим импульсом будет увеличиваться и всего через несколько импульсов может приблизиться к критической температуре воды $T_{c} \approx 647 \mathrm{~K}$. Это приведет к взрывному кипению воды с образованием быстро расширяющегося парогазового пузырька $[6,8]$. В этом случае генерация звука будет происходить уже по механизму термокавитации $[6,8,10]$, и она будет существенно более эффективной, уступая по эффективности случаю оптического пробоя [11]. Если следовать этой модели, то генерация самого мощного акустического пика $\sim 10 \mathrm{kHz}$ (рис. 2) происходит при последовательном нагреве среды сериями из десяти лазерных импульсов.

Проведенные эксперименты показали, что при нагреве тонкого слоя воды вблизи рабочего торца волокна лазерным излучением кипение воды переходит в режим, имеющий все признаки СПК $[1,5]$ : 
1) большая величина удельного теплового потока;

2) характерные звуковые эффекты;

3) гидродинамические возмущения большего по сравнению с размерами нагревателя масштаба;

4) критическая зависимость возникновения режима от мощности.

Важно, что при лазерном нагреве, так же как и в случае проволочных нагревателей, происходит кавитационная эрозия поверхности твердого тела.

Хорошо известно, что проблема возникновения ограничения теплоотдачи от проволочного нагревателя связана с тем, что при определенной его температуре режим „пузырькового кипения“ переходит в режим „пленочного кипения“. В результате эффективность нагревателя резко падает [1]. Использование лазерного излучения позволяет преодолеть эту проблему, поскольку оно легко проходит сквозь парогазовые пузырьки и пленку и полностью поглощается в жидкости за ними. В нашем случае при лазерной мощности $20 \mathrm{~W}$ мы получили рекордные значения тепловых потоков до $0.16 \mathrm{MW} / \mathrm{cm}^{2}$.

Отметим, что в настоящей работе не рассматривался вопрос о том, где именно происходит изначальная нуклеация в жидкости: вблизи торца волокна (гомогенная нуклеация) или на его поверхности (гетерогенная нуклеация). С одной стороны, поверхностная температура из-за теплопроводности кварца может быть ниже, чем в ближайших слоях воды, нагреваемых лазерным излучением. С другой стороны, по сравнению с гетерогенной (на поверхности торца) для гомогенной нуклеации требуются значительно большие перегревы [12].

Таким образом, экспериментально обнаружено возникновение режима СПК воды, инициированного $100 \mathrm{~ns}$ импульсным лазерным нагревом тонкого слоя воды вблизи торца оптического волокна.

Работа выполнена при поддержке Министерства науки и высшего образования (Государственное задание ФНИЦ „Кристаллография и фотоника“ РАН в части лазероиндуцированной термокавитации), грантов РФФИ № 17-02-00832 в части транспорта, № 18-02-00165 в части гетерогенного кипения, № 18-29-06056 в части сверхкритических флюидов.

\section{Список литературы}

[1] Zhukov S.A., Afanas'ev S.Yu., Echmaev S.B. // Int. J. Heat Mass Transfer. 2003. Vol. 46. N 18. P. 3411-3427.

[2] Kumagai S., Kawabata K., Katagari T., Shimada R. // Proc. 11th Int. Heat Transfer Conf. Kyongju, Korea. 1998. Vol. 2. P. 279.

[3] Kumagai S., Uhara T., Nakata T., Izumi M. // Proc. 5th ASME/JSME Joint Eng. Conf. San Diego, 1999. AJTE 99-6430.

[4] Zeigarnik Y.A., Platonov D.N., Khodakov K.A., Shekhter Y.L. // High Temperature. 2011. Vol. 49. N 4. P. 566-570.

[5] Чудновский В.М., Юсупов В.И., Жуков С.А., Ечмаев С.Б., Баграташвили В.Н. // ДАН. Т. 473. № 5. С. 533-535.
[6] Чудновский В.М., Юсупов В.И., Дыдыкин А.В., Невожсай В.И., Кисилев А.Ю., Жуков С.А., Баграташвили В.Н. // Квантовая электроника. 2017. Т. 47. № 4. C. $361-370$.

[7] Deng R., He Y., Qin Y., Chen Q., Chen L. // Yaogan Xuebao - J. Remote Sensing. 2012. Vol. 16. N 1. P. 192-206.

[8] Rastopov S.F., Sukhodolsky A.T. Sound generation by thermocavitation induced CW-laser in solutions. Proc. SPIE. 1991. Vol. 1440. P. 127.

[9] Gregorcic P., Jezersek M., Mozina J. // J. Biomed. Optics. 2012. Vol. 17. N 7. P. 075006.

[10] Юсупов В.И., Коновалов А.Н., Ульянов В.А., Баграташвили В.Н. // Акустический журнал. 2016. Т. 62. № 5. С. 531539.

[11] Буланов А.В., Нагорный И.Г., Соседко Е.В. // ЖТФ. 2013. T. 83. Вып. 8. С. 117-120.

[12] Novak B.R., Maginn E.J., McCready M.J. // Phys. Rev. B. 2007. Vol. 75. N 8. P. 085413. 